УДК 504.062.4

DOI: $10.36718 / 1819-4036-2020-3-11-19$
О.И. Иванова, О.П. Колпакова,

С.А. Мамонтова, Ю.П. Ковалева

\title{
ОЦЕНКА РАЦИОНАЛЬНОГО ИСПОЛЬЗОВАНИЯ ПРИРОДНЫХ РЕСУРСОВ ПРИ ОТКРЫТЫХ ГОРНЫХ РАБОТАХ
}

\author{
O.I. Ivanova, O.P. Kolpakova, \\ S.A. Mamontova, Yu.P. Kovaleva
}

\section{THE ASSESSMENT OF RATIONAL USE OF NATURAL RESOURCES IN OPEN-PIT MINING}

Иванова Ольга Игоревна - канд. геогр. наук, доц. каф. природообустройства Красноярского государственного аграрного университета, г. Красноярск. E-mail: ivolga49@yandex.ru

Колпакова Ольга Павловна - канд. с.-х. наук, доц. каф. землеустройства и кадастров Красноярского государственного аграрного университета, г. Красноярск. E-mail: olakolpakova@mail.ru

Мамонтова Софья Анатольевна - канд. экон. наук, доц. каф. землеустройства и кадастров Красноярского государственного аграрного университета, г. Красноярск. E-mail: ivolga49@yandex.ru

Ковалева Юлия Петровна - канд. биол. наук, доц. каф. землеустройства и кадастров Красноярского государственного аграрного университета, г. Красноярск. E-mail: ivolga49@yandex.ru

Цель исследования - изучение методов рационального использования и охраны природных ресурсов при ведении открытых горных работ. Проведены анализ и оценка рационального использования и охраны природных ресурсов на примере отработанного карьера «Золотая Тырада» месторождения золота, расположенного в Енисейском районе Красноярского края. Изучены технологии, применяемые для рационального использования и охраны природных ресурсов при ведении открытых горных работ. Результаты оценки влияния карьера «Золотая Тырада» на природнье ресурсы следующие: соблюдаются требования рационального землепользования, произошло уменьшение потерь земельных ресурсов под внешними отвалами в связи с отказом от части испрашиваемых земель, для минимизации грузооборота и сохранения лесов 1-й группь;; в связи с коротким сроком отработки месторождения происходил минимальный разрыв по времени между нарушением и восстановле-
Ivanova Olga Igorevna - Cand. Geogr. Sci., Assoc. Prof., Chair of Environmental Engineering, Krasnoyarsk State Agrarian University, Krasnoyarsk. E-mail: ivolga49@yandex.ru

Kolpakova Olga Pavlovna - Cand. Agr. Sci., Assoc. Prof., Chair of Land Management and Inventories, Krasnoyarsk State Agrarian University, Krasnoyarsk.

E-mail: olakolpakova@mail.ru

Mamontova Sofya Anatolyevna - Cand. Econ. Sci., Assoc. Prof., Chair of Land Management and Inventories, Krasnoyarsk State Agrarian University, Krasnoyarsk, E-mail: ivolga49@yandex.ru

Kovalyova Yulia Petrovna - Cand. Biol. Sci., Assoc. Prof., Chair of Land Management and Inventories, Krasnoyarsk State Agrarian University, Krasnoyarsk.

E-mail: ivolga49@yandex.ru

нием земель; фрактическая высота и площадь отвалов вскрышных пород не превысили проектную, корректировка конфигурации отвалов позволила снизить влияние работ на окружающую среду, избежать размещения части отвалов в водоохранной зоне реки Тырада; в связи с нагорно-глубинным типом карьера, большая часть которого расположена значительно выше господствующего уровня поверхности, загрязнения подземных водоносных горизонтов водами карьера «Золотая Тырада» не происходило и происходить не будет, искусственный водоем карьера является аккумулятором для ливневых и талых вод; мероприятия по рациональному использованию воды по сбору, очистке сточных вод, отсутствию сброса сточных вод в ручей Валунный позволили обеспечить воздействие на водные ресурсы на допустимом уровне; вырубка лесов уменьшила поверхностный сток в допустимых пределах и не привела к видимым изменениям гидрологических характеристик поверхност- 
ных водотоков района; прекращение горных работ позволит восстановить гидрологический режим района месторождения.

Ключевые слова: рациональное природопользование, рекультивация, отработанный карьер, месторождение, балансовые запасы, горные работы, вскрышные породы, водоохранные зоны.

The purpose of the research was to study the methods of rational use and protection of natural resources when conducting open-pit mining operations. The analysis and the assessment of rational use and protection of natural resources on the example of gold mine "Zolotaya Tyrada" located in the Yenisei district of Krasnoyarsk Region were carried out. The technologies applied to rational use and protection of natural resources when conducting open mining operations were studied. The results of the assessment of the influence of the career " Zolotaya Tyrada" on natural resources were the following: the requirements of rational land use were observed, there was a reduction of losses of land resources under external dumps in connection with refusal of part of desired lands, for minimization of turnover and preservation of the woods of the 1-st group; in connection with the short term of working off the field there was the minimum gap on time between the violation and restoration of lands; actual height and the area of dumps of overburden rocks did not exceed the design, correction of dumps configuration allowed to reduce the influence of works on the environment, to avoid the placement of part of dumps in water protection to a zone of the river of Tyrada; in connection with mountain and deep type of the career which most part was located much above the dominating level of the surface, pollution of underground waterbearing horizons career waters "Zolotaya Tyrada" did not happen and would not occur, artificial reservoir of the career was the accumulator for storm and thawed snow; the actions for rational use of water for collecting, sewage treatment, the lack of dumping of sewage in a stream Valunny allowed to provide the impact on water resources at admissible level; deforestation reduced superficial drain in admissible limits and did not lead to visible changes of hydrological characteristics of superficial water currents of the area; the termination of mining op- erations will allow to restore hydrological the mode of the region of the field.

Keywords: rational environmental management, reclamation, spent quarry, field, balance reserves, mining operations, overburden rocks, water protection zones.

Введение. Рациональное природопользование включает извлечение, переработку, охрану, воспроизводство природных ресурсов, использование, охрану естественных условий жизни человека, сохранение экологического равновесия природных систем. При организации рационального природопользования необходима разработка и соблюдение взаимодействия производственной деятельности человека с окружающей природной средой, применение методов хозяйствования, которые учтут естественное равновесие окружающей среды и улучшат природный потенциал [1]. В соответствии со ст. 26 Закона РФ «О недрах» от 21.02.1992 № 2395-19 предприятия по добыче полезных ископаемых и подземные сооружения, не связанные с добычей полезных ископаемых, подлежат ликвидации или консервации по истечении срока действия лицензии или при досрочном прекращении пользования недрами [2]. Федеральным законом «О промышленной безопасности опасных производственных объектов» № 116-Ф3 от 21.07.1997 г. утверждены требования по обеспечению промышленной и экологической безопасности, порядок ведения работ по технической ликвидации отработанного карьера, проведения горно-экологического мониторинга, обеспечивающего сохранность месторождения и горных выработок после ликвидации [3]. Охрана недр и окружающей среды осуществляется по «Инструкции о порядке ведения работ по ликвидации и консервации опасных производственных объектов, связанных с пользованием недр» № 33 от 02.06.1999 г. [4]. На завершающем этапе разработки месторождения производится рекультивация, которая является технологическим этапом горного производства и проводится, как правило, в три этапа. Предприятие, которое разрабатывает полезные ископаемые, обеспечивает техническую рекультивацию, которая проходит в процессе эксплуатации карьера и зависит от региональных условий [5]. Пользование недрами невозможно без нарушения земель, особенно при открытом способе разра- 
ботки месторождений. Данный способ является менее опасным в отличие от подземного, с меньшей себестоимостью и более высокими показателями извлечения полезных ископаемых из недр. Однако этому способу присуща наибольшая землеемкость за счет роста отходов горнодобывающего и перерабатывающего производства. К технологии открытых горных работ предъявляются следующие требования рационального землепользования: минимальная землеемкость; минимальный разрыв по времени между нарушением и восстановлением земель; формирование выработанного пространства и отвалов должно отвечать требованиям рекультивации и дальнейшего использования восстанавливаемых земель.

Цель исследования: изучение методов рационального использования и охраны природных ресурсов при ведении открытых горных работ.

Задачи исследования: 1) изучить методы, применяемые для рационального использования и охраны природных ресурсов при ведении открытых горных работ; 2) провести анализ рационального использования и охраны природных ресурсов при ликвидации отработанного карьера «Золотая Тырада», расположенного в Енисейском районе Красноярского края; 3) оценить влияние отработки карьера «Золотая Тырада» на природные ресурсы района.

Объектом исследования являются методы рационального природопользования при открытом способе разработки месторождений.

Методы исследования. Для выполнения исследования применены методы наблюдения и анализа, которые были использованы в изучении проведения оценки влияния открытых горных работ на природные ресурсы. Одним из направлений решений проблемы сбережения земли при открытой разработке может служить выработанное пространство карьера для складирования вскрышных пород [6]. Уменьшение потерь земельных ресурсов под внешними отвалами возможно за счет правильного выбора технологии формирования и расположения отвалов и их параметров. Ускоренное возведение внешнего отвала на проектную высоту уменьшит объем планировочных работ при проведении рекультивации. При увеличении высоты отвала в два раза уменьшится землеемкость отвальных работ, но усложнятся условия рекультивации и увеличатся транспортные затраты [7]. Для дальнейшего восстановления земель необходимо переформировать техногенный рельеср. Целесообразно вести планировочные работы сразу после складирования, чтобы избежать осадки вскрышных пород в отвале. Преждевременное нанесение плодородного слоя почвы без учета осадки может привести к потерям [7, 8]. Для рационального использования природных ресурсов Институтом проблем комплексного освоения недр РАН предложено комплексное освоение месторождений открытого и подземного способов добычи полезных ископаемых, при котором используются отходы выщелачивания руд и отвалы горного производства в технологии закладки выработанного пространства. Регулирование рационального природопользования при открытой отработке месторождений включает в себя, в первую очередь, соблюдение нормативов по выбросам и сбросам вредных веществ в атмосфреру, гидросфреру и загрязнение земель [1]. Не целесообразно размещать отвалы вскрышных пород вдали от карьерных выемок: происходит загрязнение земель продуктами пыли и газа от карьерного транспорта и увеличиваются площади антропогенного ландшафтта. При планировании мероприятий, уменьшающих интенсивность пылевыделения с поверхности отвалов вскрышных пород, необходимо учитывать степень износа оборудования и регулярно осуществлять контроль за его функционированием. При рациональном использовании водных ресурсов водоохранные мероприятия должны включать различные способы по уменьшению забора воды из поверхностных и подземных источников, в процессе разработки полезных ископаемых необходимо собирать воды и повторно использовать в оборотных системах водоснабжения, внедрять малоотходные технологические процессы для снижения сброса загрязняющих веществ. В работе [9] говорится о применении простых технологий по отстаиванию вод, откаченных из карьера в земляной отстойникнакопитель, с применением горизонтального фильтра, устроенного в теле ограждающей дамбы отстойника; в качестве фильтра применяются: сено, солома, камыш, сухие ветки. Карьерная вода после очистки используется для мойки автомобилей, пылеподавления, для гидропосева растений при биологической рекультивации. После отработки карьера отстойник и накопившийся в нем осадок используется для технической рекультивации карьера. При пла- 
нировании мероприятий охраны атмосферного воздуха необходимо учитывать влияние источников загрязнения: отвалов вскрышных пород; взрывных работ на карьере; транспорта всех типов, работающего на бензине и дизельном топливе [10]. Важным при рекультивации земель являются снятие, складирование, сохранение почвенно-растительного слоя [11]. Одним из требований рационального использования и охраны использования природных ресурсов при горных работах - защита от эрозии. Развитию водной эрозии способствует увеличение крутизны и длины склона. Для борьбы с эрозией почв производится террасирование откосов внешних породных отвалов и озеленение [12]. В качестве примера рассмотрим отработанный карьер «Золотая Тырада» Тырадинского месторождения золота, расположенного в Енисейском районе Красноярского края. Месторождение располагается на Среднесибирском плоскогорье, 670-700 м над уровнем моря, в районе наивысших абсолютных отметок Енисейского кряжа, в горно-таежной зоне, где преобладает среднегорный рельеф местности. Территория сильно задернована, нередко заболочена, растительность горно-таежная. Здесь берут начало реки бассейнов Подкаменной Тунгуски и Большого Пита. Продолжительная и холодная зима и короткое жаркое лето характеризуют континентальность климата района. Средняя за год температура воздуха $-5{ }^{\circ} \mathrm{C}$, продолжительность периода со снежным покровом - 225 дней, годовая норма осадков района - 480-520 мм, вы- сота снежного покрова - 1,5-2,0 м, многолетняя мерзлота отсутствует. Гидрологические условия района Тырадинского месторождения обусловлены расположением его в правой приводораздельной части долины реки Тырада, на гребне водоразделов ручьев Олений и Валунный. Ручьи Олений и Валунный являются левыми притоками реки Тырада. По сложности гидрогеологических условий Тырадинское месторождение относится к группе простых. На месторождении в зависимости от литологических особенностей и фильтрационных параметров выделяются два водоносных горизонта: первый - в образованиях коры выветривания, второй - в зоне экзогенной трещиноватости метаморфизованных пород кординской свиты верхнего протерозоя. На 01.01.2006 г. в контуре ликвидируемого карьера все балансовые запасы окисленных руд месторождения полностью отработаны. Производство горных работ на карьере осуществлялось в соответствии с проектом отработки Тырадинского золоторудного месторождения, выполненного институтом «Сибцветниипроект» [13], прошедшего экспертизу и согласованного со всеми контролирующими организациями в установленном порядке. Отработка месторождения производилась в период с июля 2003 г. по май 2005 г. Основные объекты карьера на конец отработки приведены в таблице 1. Горные выработки карьера на момент ликвидации представлены выработанным пространством (карьером) и насыпями (отвалами вскрышных пород).

Таблица 1

Площади объектов карьера «Золотая Тырада»

\begin{tabular}{|l|c|c|}
\hline \multirow{2}{*}{ Объект } & \multicolumn{2}{c|}{ Площадь га } \\
\cline { 2 - 3 } & $\begin{array}{c}\text { по проекту } \\
\text { отработки }\end{array}$ & фрактическая \\
\hline Карьер & 15,09 & 15,00 \\
\hline Промышленная площадка & 0,45 & 1,8 \\
\hline Отвалы вскрышных пород & 51,57 & 32,77 \\
\hline Склад первичных руд & 4,56 & 1,52 \\
\hline Отвал за балансовых руд & 1,93 & - \\
\hline Автодороги и съезды карьерные & 3,56 & 2,84 \\
\hline Автодорога межплощадочная & 7,50 & 7,50 \\
\hline Отстойник & 0,72 & 0,45 \\
\hline Инженерные коммуникации, В т. ч. ЛЭП-6/0,4 кВ & 3,09 & 3,09 \\
\hline Прочие & 1,33 & 9,83 \\
\hline Всего & 89,8 & 74,8 \\
\hline
\end{tabular}


Вскрышные породы, представленные скальными, полускальными и рыхлыми породами, уложены во внешний отвал, расположенный в юго-западной стороне от карьера. Положение отвала по высоте ограничено отметками 620 680 м. Согласно требованиям Постановления Правительства Российской Федерации от 23.11.1996 г. № 1404 «Об утверждении Положения о водоохранных зонах водных объектов и их прибрежных защитных полосах», действующих на момент отработки месторождения [14], и ст. 65 «Водного кодекса Российской Федерации» от 03.06.2006 № 74-Ф3 [15], отвал вскрышных пород размещен за границей водоохранных зон р. Тырада и ручья Валунного. В процессе отработки месторождения проектные решения по размещению отвалов были скорректированы с целью минимизации грузооборота и сохранения лесов 1-й группы. Занимаемая площадь отвала по проекту составляла 51,57 га, фактическая 32,77 га, соответственно количество ярусов сократилось до двух (см. табл. 1). Реализованные локальные проекты размещения вскрышных пород при отработке Тырадинского месторождения позволили: произвести рациональное изъятие и сделать минимальными сроки использования земель в технологическом процессе отработки месторождения; сфрормировать оптимальные по форме, структуре и устойчивости отвалы; снизить воздействие на окружающую среду за счет удаления проектных границ отвала от близрасположенных водоемов ручья Валунного, реки Тырады; достигнуть снижения затрат на отвалообразование за счет сокращения расстояния откатки вскрышных пород в отвал; отказаться от части испрашиваемых земель для размещения отвалов на землях с лесами 1-й группы. Приток поверхностных вод в карьер был только за счет выпадения дождя на территорию карьера. Поверхностный сток с возвышенности, расположенной с северной стороны карьера, не попадает в карьер, стекает вдоль породного вала, ограждающего карьер к кювету дороги, по естественному уклону рельефра в ручей. Учитывая малый срок отработки месторождения и объемы извлекаемой горной массы, нарушение гидрогеологического режима подземных вод за период эксплуатации было минимальным, значительных притоков подземных вод в карьер не наблюдалось. Это объясняется следующими факторами: нагорноглубинным типом карьера, большая часть которого расположена значительно выше господствующего уровня поверхности; наличием геологоразведочной штольни на высоте 658 м; коротким сроком доработки нижних горизонтов карьера в зимний период 2004-2005 гг. В связи с этим горные работы велись без предварительного осушения. При отработке Тырадинского месторождения сброс карьерных вод в водный объект ручей Валунный не осуществлялся. После завершения горных работ, с апреля 2005 г. началось постепенное заполнение выработанного пространства поверхностными и грунтовыми водами. Ко второму кварталу 2006 г. уровень воды в карьере достиг своего гидростатического уровня и незначительно менялся в зависимости от периода времени года в отметках 640, 645 м (рис. 1). Воды, поступающие в выработанное пространство карьера, из-за существенно щебнистого состава массива пород (коэффициенты фильтрации до 7,66 м/сут) дренировали по склону в сторону ручья Валунного. Расчеты показывают, что даже при выпадении максимального суточного объема осадков (56 мм) переполнение карьерной выемки не произойдет, так как минимальное расстояние от отметки зеркала воды до верхней кромки борта карьера будет составлять не менее 15-20 м (см. рис. 1). Амплитуда колебаний отметок воды по скважинам в паводковый период (в период отработки) достигала 20 м, что также косвенно указывает на высокие фильтрационные свойства пород. Уровень воды в карьере установился на отметке 645 м при уровне воды ручья Валунный 635 м. Это значит, что закончилось формирование водоема в выработанном пространстве карьера. Схемы формирования подземного и поверхностного стока до и после производства горных работ на карьере «Золотая Тырада» приведены на рисунках 2, 3. Согласно рисункам 2, 3, произошло изменение в формировании поверхностного и подземного стока в ручей Валунный. 


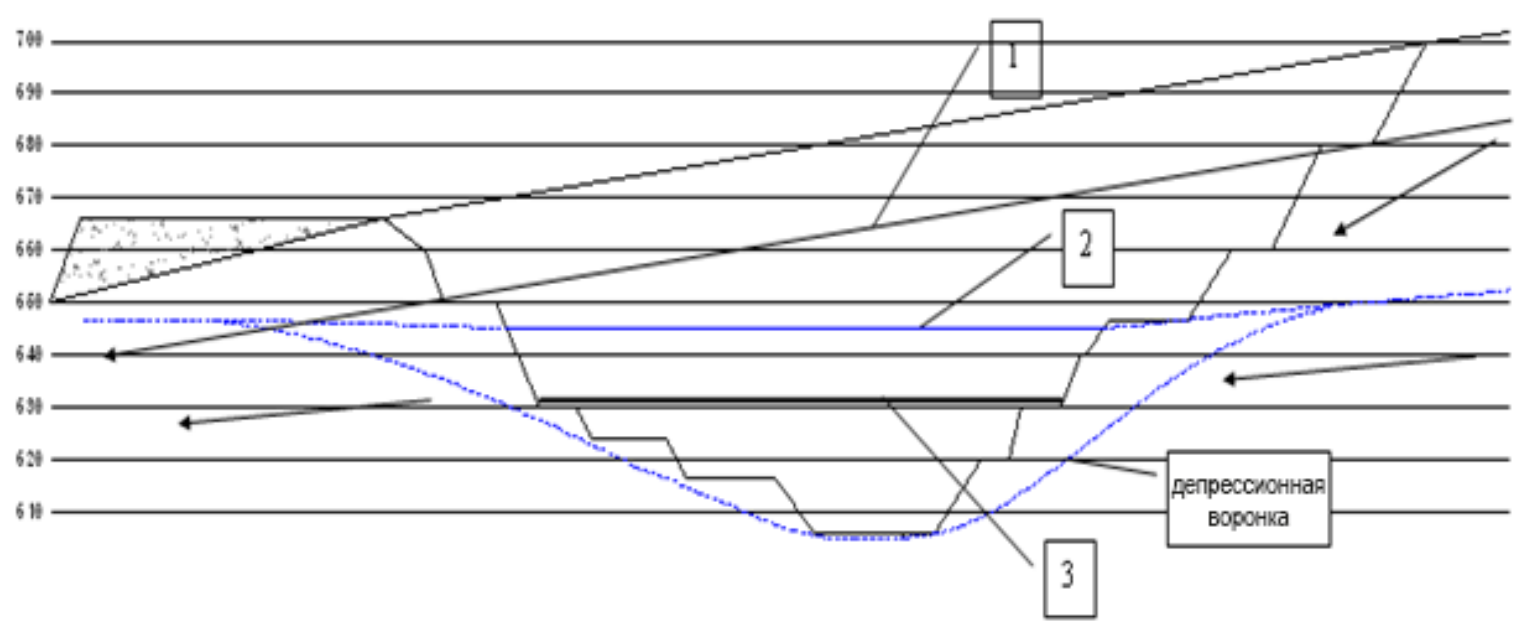

Puc. 1. Схема движения подземных вод (показана стрелками) после ликвидации карьера:

1 - уровень грунтовых вод до отработки карьера; 2 - максимальный уровень воды в водоеме карьера; 3 - сформировавшийся (гидростатический) уровень воды

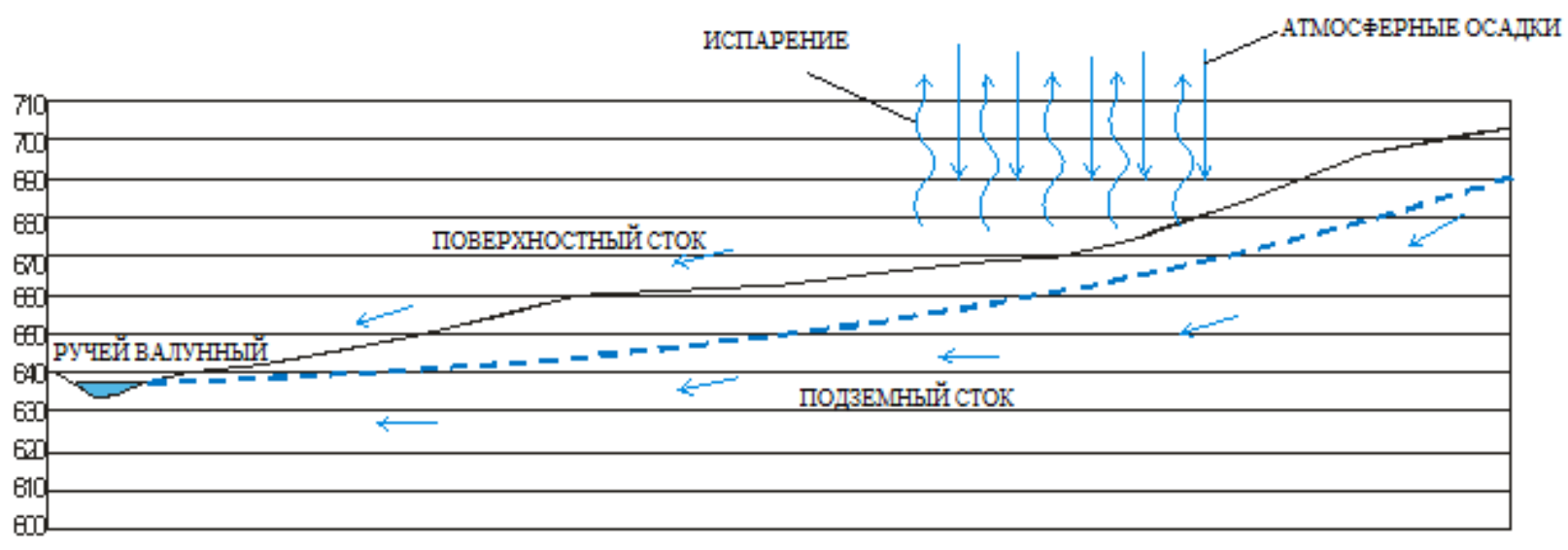

Puc. 2. Схема формирования подземного и поверхностного стока на карьере «Золотая Тырада» до производства работ

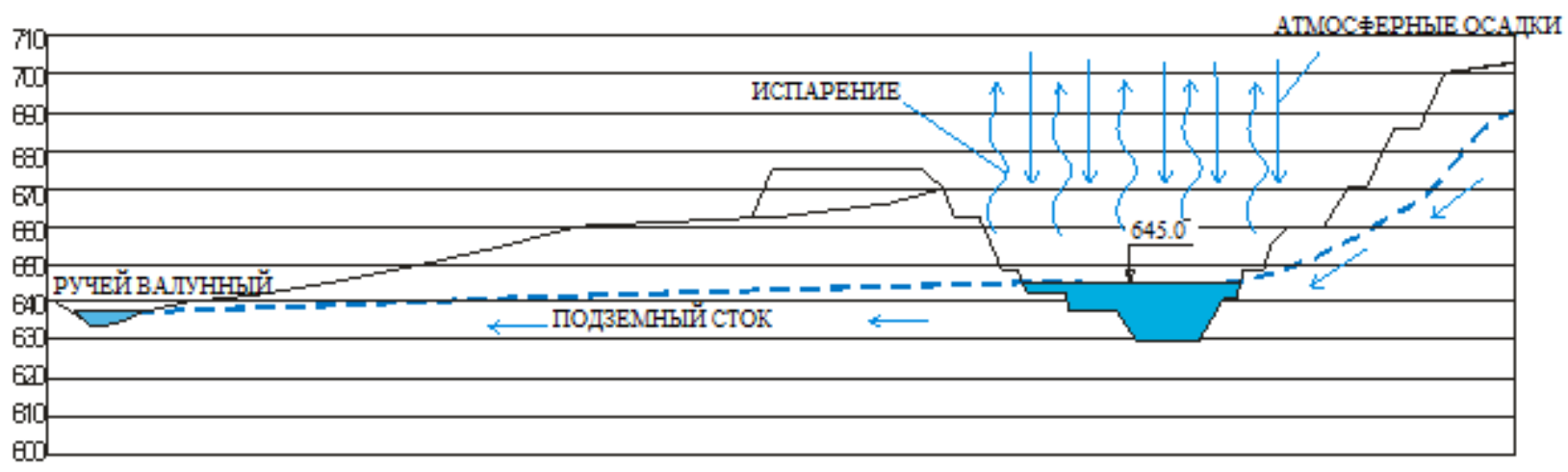

Puc. 3. Схема формирования подземного и поверхностного стока на карьере «Золотая Тырада» после завершения горных работ 
Произошло уменьшение поверхностного стока, но при этом увеличился подземный сток, поскольку существует гидравлическая связь между водоемом в выработанном пространстве карьера и ручья Валунного через трещинножильные воды в породах верхнекординской подсвиты верхнепротерозойского возраста. Влияние карьера на водообильность ручья Валунного можно оценить как потери на испарение с зеркала искусственных водоемов в выработанном пространстве карьера. Расчет потерь воды на испарение за сезон (год):

$$
q=\frac{B \cdot S}{1000}=\frac{250 \cdot 35000}{1000}=8750 \mathrm{~m}^{3} / \text { год, или } 0,28 \mathrm{л} / \mathrm{c},
$$

где $B$ - величина испарения для ландшафтной зоны, соответствующей зоне месторождения, составляет 250 мм (м/год) (СН ИП 2.06.14-85) [16]; S - площадь поверхности, с которой происходит испарение, м². $^{2}$

Из приведенных расчетов следует, что влияние карьера на водообильность ручья Валунного незначительно. Искусственный водоем карьера будет являться аккумулирующим водоемом для ливневых и талых вод, что будет выражаться в уменьшении влияния паводков на ручей Валунный. Разгрузка аккумулированной воды будет происходить в меженный период, поэтому в этот период водообильность ручья Валунного должна повыситься. Воздействие на поверхностные воды выразилось в снижении стока в водные объекты в результате вырубки лесов. Незначительная площадь месторождения 0,748 км² [13], при общей площади водосбора водотоков 10,5 км²$^{2}$, что составляет $7,1 \%$ при допустимом значении $10 \%$, а также небольшой период отработки месторождения (2 года), - говорят о том, что вырубка лесов уменьшила поверхностный сток в допустимых пределах и не привела к видимым изменениям гидрологических характеристик поверхностных водотоков района. Сток поверхностных нестесодержащих отходов с промышленной площадки, автозаправки, автостоянки осуществлялся по уклонам спланированной поверхности к колодцу, оборудованному специальным устройством для сбора крупных взвешенных частиц, после чего отводился в отстойник. После завершения отработки карьера проведены работы по удалению насосных агрегатов, демонтажу водоводов, засыпке дождеприемного колодца, отстойника, вывозу промышленного мусора из выработанного пространства, предусмотренные проектом отработки. Химический состав вод, образующихся в карьере, выполнен санитарно-промышленной лабораторией Олимпиадинского ГОКа [13]: $\mathrm{pH}$ - 6,8; БПК полн - 2,8 мг/л; взвешенных веществ - 1,2 мг/л; нефтепродуктов - 0,04; меди 0,0009 ; цинка - 0,01; марганца - 0,011; железа 0,15 ; свинца - 0,0095; никеля - 0,01; сухого остатка - 183,8 мг/л. Химический состав карьерных вод в целом удовлетворяет нормативам рыбохозяйственного водопользования, за исключением концентрации марганца и железа. Повышенное содержание марганца и железа в водных объектах района имеет природное происхождение.

\section{Выводы}

1. Изучены технологии, применяемые для рационального использования и охраны природных ресурсов при ведении открытых горных работ.

2. Проведен анализ рационального использования и охраны природных ресурсов при отработке карьера «Золотая Тырада».

3. Результаты оценки влияния карьера «3олотая Тырада» на природные ресурсы следующие: соблюдались требования рационального землепользования, произошло уменьшение потерь земельных ресурсов под внешними отвалами в связи с отказом от части испрашиваемых земель для минимизации грузооборота и сохранения лесов 1-й группы; в связи с коротким сроком отработки месторождения происходил минимальный разрыв по времени между нарушением и восстановлением земель; фактическая высота и площадь отвалов вскрышных пород не превысили проектную, корректировка конфигурации отвалов позволила снизить влияние работ на окружающую среду, избежать размещения части отвалов в водоохраной зоне реки Тырада; в связи с нагорно-глубинным типом карьера, большая часть которого расположена 
значительно выше господствующего уровня поверхности, загрязнения подземных водоносных горизонтов водами карьера «Золотая Тырада» не происходило и происходить не будет, искусственный водоем карьера является аккумулятором для ливневых и талых вод; мероприятия по рациональному использованию воды по сбору, очистке сточных вод, отсутствию сброса сточных вод в ручей Валунный позволили обеспечить воздействие на водные ресурсы на допустимом уровне; вырубка лесов уменьшила поверхностный сток в допустимых пределах и не привела к видимым изменениям гидрологических характеристик поверхностных водотоков района; прекращение горных работ позволит восстановить гидрологический режим района месторождения.

\section{Литература}

1. Васильчук М.П., Зимич В.С. Недра и основные положения экологической безопасности их освоения // Горный журнал. 2013. № 7. С. 17-21.

2. О недрах: федер. закон Российской Федерации от 21.02.1992 № 2395-19 (ред. от 27.12.2019) // Российская газета. 1992. № 102 (5 мая).

3. О промышленной безопасности опасных производственных объектов: федер. закон от 21.07.1997 № 116-Ф3 (ред. от 29.07.2018 № 271-Ф3) // Собрание законодательства Российской Федерации. 1997. № 30 (28 июля). Ст. 3588.

4. Инструкция о порядке ведения работ по ликвидации и консервации опасных производственных объектов, связанных с пользованием недрами: утв. пост. Госгортехнадзора России от 02.06.1999 № 33 // Российская газета. 1999. № 164 (24 авг.).

5. Иванова О.И. Особенности рекультивации земель, нарушенных горными работами, на территории Енисейского района Красноярского края // Современные проблемы землеустройства, кадастров и природообустройства: мат-лы национал. науч. конф. I Краснояр. гос. аграр. ун-т. Красноярск, 2019. C. 115-123.
6. Крупник Л.А., Пятигорский Л.В. Совершенствование массивов из твердой закладки / КазНИИНТИ. Алма-Аты, 1987. С. 64.

7. Коваленко В.С., Штейнцайг Р.М., Голик Т.В. Рекультивация нарушенных земель на карьерах: учеб. пособие: в 2 ч. Ч. 1 / Москов. гос. горный ун-т. М., 2008.66 с.

8. Томаков П.И., Коваленко В.С. Рациональное землепользование при открытых горных работах. М.: Недра, 1984. 213 с.

9. Васильев В.И., Вололщук Е.А. Простые сооружения для очистки промстоков // Вестник УГТУ-УПИ. Строительство и образование. Екатеринбург, 2005. Вып. 14. C. 362-364.

10. Меньшиков В.В., Швыряев А.А. Опасные химические объекты и техногенный риск. М: Изд-во МГУ им. М.В. Ломоносова, 2003. $254 \mathrm{c}$.

11. Трубецкой К.Н., Галченко Ю.П., Бурцев Л.И. Охрана окружающей среды при освоении недр // Вестник РАН. 1998. Т. 68. C. 629-637.

12. Бурыкин А.М., Пигорев И.Я. Эродируемость вскрышных пород техногенного ландшафрта и некоторые приемы борьбы с эрозией (на примере Стойленского ГОКа) // Рекультивация земель, нарушенных горными работами на КМА. Воронеж, 1985. С. 85-103.

13. Проект отработки Тырадинского золоторудного месторождения / Сибцветметниипроект. Красноярск, 2000.

14. О водоохранных зонах водных объектов и их прибрежных защитных полосах: постановление Правительства России от 23.11.1996 № 1404 // Собрание законодательства Российской Федерации. 1996. № 237 (12 дек.).

15. Водный кодекс Российской Федерации от 03.06. 2006 № 74-Ф3 (ред.от 27.12.2019 г. № 488-Ф3) // Российская газета. 2006. № 121 (8 июня).

16. СНиП 2.06.14-85. Защита горных выработок от подземных и поверхностных вод // URL: http://docs.cntd.ru. 


\section{Literatura}

1. Vasil'chuk M.P., Zimich V.S. Nedra i osnovnye polozhenija jekologicheskoj bezopasnosti in osvoenija // Gornyj zhurnal. 2013. № 7. S. 17-21.

2. O nedrah: feder. zakon Rossijskoj Federacii ot 21.02.1992 № 2395-19 (red. ot 27.12.2019) // Rossijskaja gazeta. 1992. № 102 (5 maja).

3. O promyshlennoj bezopasnosti opasnyh proizvodstvennyh ob\#ektov: feder. zakon ot 21.07.1997 № 116-FZ (red. ot 29.07.2018 № 271-FZ) II Sobranie zakonodatel'stva Rossijskoj Federacii. 1997. № 30 (28 ijulja). St. 3588.

4. Instrukcija o porjadke vedenija rabot po likvidacii i konservacii opasnyh proizvodstvennyh ob'ektov, svjazannyh s pol'zovaniem nedrami: utv. post. Gosgortehnadzora Rossii ot 02.06.1999 № 33 // Rossijskaja gazeta. 1999. № 164 (24 avg.).

5. Ivanova O.I. Osobennosti rekul'tivacii zemel', narushennyh gornymi rabotami, na territorii Enisejskogo rajona Krasnojarskogo kraja /I Sovremennye problemy zemleustrojstva, kadastrov i prirodoobustrojstva: mat-ly nacional. nauch. konf. / Krasnojar. gos. agrar. un-t. Krasnojarsk, 2019. S. 115-123.

6. Krupnik L.A., Pjatigorskij L.V. Sovershenstvovanie massivov iz tverdoj zakladki I KazNIINTI. Alma-Aty, 1987. S. 64.

7. Kovalenko V.S., Shtejncajg R.M., Golik T.V. Rekul'tivacija narushennyh zemel' na kar'erah: ucheb. posobie: v 2 ch. Ch. 1 / Moskov. gos. gornyj un-t. M., 2008. $66 \mathrm{~s}$.
8. Tomakov P.I., Kovalenko V.S. Racional'noe zemlepol'zovanie pri otkrytyh gornyh rabotah. M.: Nedra, 1984. $213 \mathrm{~s}$.

9. Vasil'ev V.I., Vololshhuk E.A. Prostye sooruzhenija dlja ochistki promstokov /I Vestnik UGTU-UPI. Stroitel'stvo i obrazovanie. Ekaterinburg, 2005. Vyp. 14. S. 362-364.

10. Men'shikov V.V., Shvyrjaev A.A. Opasnye himicheskie ob\#ekty i tehnogennyj risk. M: Izdvo MGU im. M.V. Lomonosova, 2003. $254 \mathrm{~s}$.

11. Trubeckoj K.N., Galchenko Ju.P., Burcev L.I. Ohrana okruzhajushhej sredy pri osvoenii nedr /l Vestnik RAN. 1998. T. 68. S. 629-637.

12. Burykin A.M., Pigorev I.Ja. Jerodiruemost' vskryshnyh porod tehnogennogo landshafta i nekotorye priemy bor'by s jeroziej (na primere Stojlenskogo GOKa) // Rekul'tivacija zemel', narushennyh gornymi rabotami na KMA. Voronezh, 1985. S. 85-103.

13. Proekt otrabotki Tyradinskogo zolotorudnogo mestorozhdenija / Sibcvetmetniiproekt. Krasnojarsk, 2000.

14. O vodoohrannyh zonah vodnyh ob'ektov $i$ ih pribrezhnyh zashhitnyh polosah: postanovlenie Pravitel'stva Rossii ot 23.11.1996 № 1404 // Sobranie zakonodatel'stva Rossijskoj Federacii. 1996. № 237 (12 dek.).

15. Vodnyj kodeks Rossijskoj Federacii ot 03.06 . 2006 № 74-FZ (red.ot 27.12.2019 g. № 488$\mathrm{FZ)} \mathrm{//} \mathrm{Rossijskaja} \mathrm{gazeta.} \mathrm{2006.} \mathrm{№} 121$ (8 ijunja).

16. SNiP 2.06.14-85. Zashhita gornyh vyrabotok ot podzemnyh i poverhnostnyh vod // URL: http://docs.cntd.ru. 